\title{
Draw Me a Shepherd: Student-teachers' Perceptions and Metaphors on the Image of the "Leader-teacher"
}

\author{
Yonit Nissim ${ }^{1}$ \\ ${ }^{1}$ Ohalo College Katzrin Israel, Israel \\ Correspondence: Yonit Nissim, Ohalo College Katzrin Israel, Israel. E-mail: yonitn@ohalo.ac.il
}

Received: January 15, 2020

Accepted: March 4, $2020 \quad$ Online Published: March 9, 2020

doi:10.5539/hes.v10n2p24

URL: https://doi.org/10.5539/hes.v10n2p24

\begin{abstract}
The current research examined how students participating in professional training in education and teaching characterized the concept of the "teacher leader". Layered analysis was employed using quantitative data alongside a qualitative examination of metaphorical representations indicating deeper unconscious perceptions.

The significance of the investigation lies in revealing the meaning given in the student-teachers' reflective worldview to their future role as teachers and educational leaders. Participants were one hundred twenty-five undergraduate students studying in various stages of their B.Ed. courses in education and teaching at a teacher education college in Israel.

The research process identified four key indices, describing the main qualities required for the teacher leader: Personal Relations, Student Empowerment, Personality Traits, and Functional Traits. Key findings indicated that, according to the students' opinions, Personal Attitude received the highest score of the four examined indices. Thus, from the perspective of these future teachers, a clear association was created between Personal Relations and Personality Traits, as the most significant dominant traits in the concept of the "teacher leader".
\end{abstract}

Keywords: teacher leader, metaphor, educational leadership, teacher training

\section{Theoretical Background}

According to Ronald (2001) "Leaders are shepherds". This is a conventional thinking about the leader as a person who protects and cares for his flocks. This metaphorical illustration needs an in-depth investigation, but metaphors are important since they can serve as underlying, organizing structures of leadership thinking, and experience. Metaphors can also be mobilized in order to accomplish interpersonal goals (Oberlechner \& Mayer-Schmnberger, 2002).

In the present study, I would like to broaden the investigation and throw a spotlight on the views of student teachers taking their first steps in the teaching training process, during their undergraduate studies. The trigger for this research occurred when I taught the subject of teacher empowerment and leadership in one of my seminars, the students were asked to respond to the question: What is educational leadership? Their responses included several metaphors comparing leadership to artistic-narrative or visual images.

Educational leadership theories and approaches are discussed extensively in teaching training processes (for example: Agosto \& Roland, 2018; Capper, 2015; Rousmananier, 2017). Different theories envisage different conceptualizations of educational leadership. Over time these different theoretical approaches have developed from "educational management" seen as a purely administrative role to "educational leadership" that envisages the educator as playing a fuller, central role in the organization (Bush, 2011; Gunter, 2004). In the 1980s, theory in this field saw the educational organization and its goals as the center of leadership research. From the end of the 1980s the focus shifted to human resources and individualist methodologies. This alteration in focus led to greater discussion of the educational leader (Evers \& Lakomski, 2013). A dramatic growth of rich research was prompted by many new definitions and conceptualizations of educational leadership. At the beginning of the $21^{\text {st }}$ century and more intensively in the last decade, there has been a flood of literature discussing the nature of educational leadership, and the rapid dynamic changes that the introduction of technology have wrought for the shaping and operational role of the educational leader (Friedman, 2016; Hallinger, 2017; Hallinger \& Bryant, 2013; Hallinger \& Chen, 2015; McNeill \& Engelke, 2014; Oplatka \& Arar, 2017). This alteration led Yukl (2002) to note: 
Leadership is very arbitrary, and subjective and there are no correct or mistaken definitions in contrast to others. Thus, the different definitions are context dependent, requiring accurate conceptualization that will outline boundaries of the theoretical frame in an appropriate manner for the discussed issue (pp. 4-5).

Fundamental questions are raised regarding the leader's professional identity construction and learning, examining educational leadership models, and establishing and developing optimal high-quality teaching methods.

Although there is wide-branching literature in this field, there is still room to examine particular teacher training practices and especially student-teachers' perceptions of the teacher as a leader, as part of their reflective thinking on their abilities, and their attempts to characterize contemporary leadership and envisage educational leadership for the future. As far as could be discovered, our research is the first to examine these perceptions in detail.

In a recent study with a colleague (Nissim \& Simon, 2019), we examined the attitudes of student-teachers studying for a master's degree in Educational Administration and Organization (M.Ed.) regarding the image of the teacher leader. Two main axes were identified in the analysis of the different findings: a high level of interpersonal relations with pupils and colleagues, and the central position of personal characteristics. We identified a main trend whereby the graduates and trainees of the program see the image of the teacher-leader as holding distinct personality traits for leadership. These characteristics were translated in practice into strategies for educational work that could empower pupils, a process which would be expressed in improved learning achievements. These findings inspired an expansion of the investigation to include the views of student-teachers studying for a Bachelor's degree in education and teaching concerning the concept of educational leadership.

The dynamically changing modern world requires the construction of new conceptualizations suitable for the new age. As mentioned above, the role of educational leadership, its definitions, and their implications have altered substantially over time. The changes in approaches to educational leadership that have been discussed and employed in the field of educational leadership are important as they affect teachers' day-to-day functioning. They are especially important for students training for the education and teaching professions who need to be up to date with advances in this area (Nissim \& Simon, 2019). As noted above, teachers need a very wide range of skills, qualities and aptitude to be able to build leadership abilities (Harrison\& Killion, 2007). Many studies have tried to understand who is the good teacher? Are teachers actually leaders? And how can educational leadership be built among tomorrow's teachers? Despite the vast amount of rich research, the identification of types of educational leadership remains enigmatic (Humphreys, 2010). Therefore, the research described here sought to thicken existing research by analyzing the perceptions of educational leadership of students, who are in the process of vocational training to become teachers

\section{Leadership}

There are various definitions of the term "leadership" in the professional literature. Over history many descriptions have been suggested to try to capture the nature of this phenomenon and its characteristics in words (Levi, 2008; Oplatka, 2005; Yukl, 2010) Various approaches are tring to explain the complexity. Yukl (2010) claimed that the new leadership theories emphasize how the leader's behaviors have symbolic value, their messages are inspiring and visionary, they employ non-verbal communication, referring to ideological values, intellectually challenging those who they lead. He noted that their subordinates expect the leader's self-sacrifice and a level of performance that exceeds their defined duties. Such leaders provide meaning for work by linking it to moral goals and commitment, instead of attempting to influence factors in the environment of those whom they lead.

\subsection{Educational Leadership}

Educational leadership necessitates being able to design and instill a vision, learning, mediating knowledge to pupils and helping them to build meaning and knowledge in collaboration with others, opening up opportunities for creativity and development, , stimulating pupils' ideas, sharing perceptions and values, knowing how to apply beliefs and information, continuously building dialog, developing new ideas, and managing reflective processes in a cooperative, moral and modern climate (Schneider, 2013).

In contrast to other leaders, an educational leader is able to exercise pedagogic-strategic discretion and not only strategic discretion. In other words, they can determine an educational goal and adapt suitable educational means to realize it. An additional characteristic of the educational leader is their conscious and reasoned educational identity (Eyal, 2004; Harpaz, 2009; Oplatka, 2005; Schneider, 2013; Vygotsky, 2004).

Three main approaches are used to define educational leadership. According to the first, the "knowledge approach", the educational leader has knowledge of matters involved in leading the educational framework. They 
also have essential skills to lead processes. However, knowledge alone is insufficient to become an educational leader. The second approach, the "characteristics approach" emphasizes various traits that characterize the educational leader, for example: integrity, balance, innovation etc. In contrast to knowledge, these traits are more personal and distinguish the educational leader. The third approach, the "identity approach" emphasizes the pedagogic identity of the leader. The educational leader has an educational goal anchored in an educational worldview. Based on this viewpoint, the leader is able to use pedagogic-strategic discretion (Harpaz, 2009). Eyal (2014) indicated that there is no single approach suitable to describe the educational leader, rather the three approaches should be integrated in appropriate amounts, according to the setting in which the leader leads. The next section describes the issue of teacher leadership, the issue at the heart of this research.

\subsection{Teacher Leadership}

The meaning and position of leadership within educational activity in general, and the role of the teacher in particular is mentioned abundantly in the relevant professional literature. "Teacher" and "leader" are interrelated concepts, since the teacher's main role is as the leader of the class (Darom, 2003). The teacher's leadership is distinguished by the character of the school climate, which they establish and uphold; when there is a healthy, free and supportive educational climate, founded on the principle of respect for others and reciprocity, common goals are achieved to an optimal extent for the teacher and their students, and positive norms of learning are developed. Additionally, the teacher should create opportunities to distribute leadership by encouraging the students to undertake and to experience a sense of responsibility and satisfaction by becoming aware of their ability to influence their peers.

The teacher-leader integrates and assists learning. They guide group processes by relating in an optimal manner both to the students and to the learning contents. They believe in the possibility of this combination and simultaneously transmit this belief to the students (Cohen, 2011).

According to Vygotsky (2004) the teacher relates to the class as a community in which the teacher is the social leader. The teacher leads the learning processes. The teacher should motivate the learners to produce personal initiatives by asking questions that stimulate the learners to respond and find answers to the questions. In this way the teacher becomes an expert in sharing and managing learning and investigative processes.

Darom (2003) claimed that teaching is one of the most difficult and complicated professions; it necessitates qualities such as sensitivity, empathy, leadership and rhetoric skills. In this context, Darom (2003,) noted that "the teacher is the leader of the class at least formally". Darling - Hammond (2005) compared the teacher to an orchestra's conductor who organizes, discerns and encourages communication to create a perfect final product. This metaphor is often depicted to illustrate the leadership phenomenon.

Shatz-Oppenheimer (2006) described the educational leader as a 'flexible teacher' as one who reacts and adapts themselves to the students in a heterogeneous class while actualizing equality of educational opportunities. Under these conditions, teaching develops and grows from the students' reactions and their personal worlds and personality; the teacher-leader acts as a model for imitation, is charismatic and knowledgeable and holds a vision. Four main characteristics are attributed to the teacher-leader are: charisma, and personal relations, constituting an intellectual challenge and setting a vision for their student - whether by their model or by setting concrete goals beyond the personal goals of each student (reference needed).

\subsection{Students' Perceptions of the Teacher Leader}

The portrait of the ideal teacher-leader in the eyes of their students has been described in educational research since the beginning of the $20^{\text {th }}$ century (Paras et al., 2005). According to Apelwig and Shalev-Wigisar (2010)) since the 1970s, the universities and colleges have given a significant place to the evaluation of their teachers' quality of teaching. Their evaluation is given a place in the lecturers' promotion, especially in colleges".

Raichal and Arnon (2005) indicated the teacher's personality is the most outstanding of the good teacher's attributes. Behaving respectfully towards students is the most central component in teacher-student relationships, alongside politeness, a sense of humor, understanding for the student's problems, offering varied activities and maintaining order and discipline. The teacher-leader's desirable attributes include being understanding and patient, willing to listen to the students, modest, polite and pleasant, demonstrating informality and simple living, participating in their students' activities, able to form good contact with the parents, comes on time to lessons, recognizes the importance and value of the student, warm and personal and does not expect that the students will be always willing to learn.

Additionally, professional teachers, like those who fill other professions, conduct a sort of contractual relationship with the students (ibid). 
Perry (2006), who discussed the perception of the good teacher's leadership in student-teachers' eyes, focusing on the personal traits of this leader, found that students attributed significant weight to leadership attributes $(\mathrm{M}=4.31)$. The students recognized the importance of leadership skills for a "good teacher" as part of the teacher's personality or functioning as can be seen in two of the students' remarks: "by the very fact of him being a good teacher, he is already a leader of some sort" and "a teacher is by nature a leader" (Perry, 2006). The teachers' consideration of their students was seen as personal and close, their students could easily approach them, and respected their intellect, integrity, love of the truth and courage.

Another example, which inspired the present research, occurred when I taught the subject of teacher empowerment and leadership. In one of the lessons the students were asked to complete sentences in writing in response to the question: what is educational leadership? This question was asked in thinking groups, and the responses included several metaphors comparing leadership to concrete, artistic-narrative images. One of the students described the leader as "a huge wave that drags many other waves after it". Another described the leader as "a person who climbs a steep hill, with many other people attached to him by ropes". A third student indicated that "leadership is a strong but gentle hand, with fingers of equal lengths, and different and varied functions that the hand that can stretch out for positive work and benefit or it can be used as a strong arm to make things bad". Others answered spontaneously: "a shepherd". The interesting discussion that ensued was a catalyst for the present study. The question is prompted: why do students use figurative metaphors to describe leadership? Is this a concept that words are insufficient to describe and so it is more convenient to use figurative language?

\subsubsection{What is Metaphorical Thinking?}

Metaphorical thinking clarifies concepts and subjects which words are inadequate to accurately describe. The metaphor creates a picture and illustrates the words in a figurative form. It is a tool that can encourage ideas, with creative power that enables thinking processes to search for ideas in areas, territories and fields of knowledge that do not immediately connect with the subject (Brown, 1993; Oberlechner \& Mayer- Schonberger, 2002). Usually, it is possible to identify these areas as belonging to the domain of nature. The use of the metaphor is essential for learning, communication and understanding. It serves as a learning mechanism that can be used to acquire new knowledge on the basis of analogy to previous knowledge. The source of the word metaphor is from the Greek: "meta" meaning change, over, across and "pherein" meaning to carry or transfer (Brown, 1993). In other words, to transfer the change. Some scholars define a "metaphor" as a type of expanded image that creates identity between two elements or attributes copied from one semantic field to another semantic field, and as a result a new verbal combination is created with surprising meaning. Another definition of metaphor relates to the transmission of a concept from a concrete area to an abstract area (Lakoff \& Johnson, 1980). Therefore, it appears that the uniqueness of the metaphor is not characterized by its belonging to language and linguistics; rather it belongs to the cognitive-perceptual domain, enabling abstract terms to become more concrete and familiar or explained in detail and expanded through the creation of a verbal drawing (Lakoff \& Schon, 1980, 1999). From all the above, we can understand that A metaphor usually serves to describe concepts that it is difficult to word, a description of an experience, situations, or understanding of complex processes through an illustration and explanation of the context and relations between different concepts, as a system composed of interactive parts. The metaphor is based on similarity between different semantic fields. As it involves analogical thinking it assists the investigation of verbal and visual processes in different fields of knowledge in general and especially in education and teaching. Metaphors can provide an organizational framework to expand understanding and reflective exploration of complex perceptions. A metaphor is a lateral thinking process that relies on understanding different and varied concepts, restructuring what is familiar and well-known and creating something new that complements longitudinal thinking (Johnson, 1979, 1983).

"Leadership" is a broad concept and to understand its full scope requires multi-faceted thinking that can be elucidated with the use of metaphors, making it more accessible and tangible. In the last two decades, metaphors have been used widely as a research tool to understand the meaning that people attribute to reality. Research studies rely on the idea that man's system of conceptualization, represents their understanding of the world, and bears an often-unconscious metaphorical character (Johnson, 1979, 1983; Lakoff \& Schon, 1980, 1999). A metaphor sometimes serves as a filter that represents the described subject in a "new light". Thus, it is possible to define a metaphor as analogical thinking, which constitutes a means to investigate verbal and visual language processes ( Singh, 2010). In the last decade, many researchers have focused on metaphors as a tool to investigate teachers' thinking. These studies have examined teachers' perceptions concerning different concepts in the education field (such as: learning, forgetfulness, school, teacher, principal etc.). This has allowed certain insights to be drawn in relation to the perception of these concepts with implications for teacher education (Noonan \& Fish, 2004; Singh, 2010). 


\subsubsection{Metaphors and Leadership}

Metaphors are useful to provide deeper understanding of leadership. Research studies have examined the dominant metaphors in best-seller books dealing with leadership. The findings of these studies indicate that the following metaphors: war, spiritual paths, team work, play, artistic creativity, natural processes, machines, professional rules or experience are dominant in the characterization and illustration of educational leadership (Singh, 2010). According to these findings, leadership metaphors can indicate the thinking, the character and purpose of leadership, the role and partnership of the leader and his or her practices, leadership activities, skills and abilities that are created around effective leadership, and can represent leadership as reflected in different cultures. In some studies, metaphors were used to bridge between theory and educational leadership practices. Some scholars have noted that: pedagogical metaphors allow a reflexive perception of insights and thoughts that dig deep into the human experience that shapes future behavior and reactions (Singh, 2010). It can be argued that metaphors enable visualization of complex concepts, and describe abstract concepts in images. Through the use of metaphors in education, students can think reflectively about their perceptions, their attitudes and personal beliefs.

\section{Methodology}

\subsection{The Purpose of the Study}

The study aimed to examine the viewpoints of student-teachers training for teaching and education professions, examining how they conceptualize the image of the "teacher leader". The data was collected in two ways: quantitatively (by rating statements) and qualitatively (through sentence completion and free writing of answers).

\subsubsection{The Research Questions}

The following questions guided the research process:

1. How do the student-teachers define the main traits that compose the figure of the "teacher-leader"?

2. How do they see the desirable figure of the "teacher-leader"? What are the most dominant leadership/meaningful traits of this figure?

3. Which metaphors do the student-teachers use to reflectively define the figure of the "teacher-leader"?

4. Are there differences by gender? age and by years of study?

5. What is the general worldview embodied in the student-teachers' approach towards the image of the teacher-leader?

\subsubsection{The Research Process}

A questionnaire was specially constructed and validated by three lecturers, each with a $\mathrm{PhD}$ in education. The reliability of each part of the questionnaire was tested separately. A one-step convenience sample was collected. The questionnaire was distributed via Google Drive to the entire mailing list of all B.Ed. and academic retraining students at the teacher education college. A total of 650 students received the questionnaire. Of these, 125 chose to respond to the questionnaire (19.2\%). The responses were given anonymously.

The research process included two research stages: The first stage involved quantitative data collection, statistical analysis and processing, the formulation of the findings and their presentation as a statistical and inferential presentation. The second stage involved qualitative research involving collection and analysis of data elicited from written responses to completion of sentences, coding of the data in categories and content analysis of the responses

\subsubsection{The Research Tool}

The questionnaire included three parts:

(1) socio-demographic data

(2) 15 statements which respondents were asked to grade on a 5-point Likert scale where $1=$ not at all and $5=$ to a large extent. The statements were divided into four dimensions: personal relations, empowerment of the pupils, personal traits and functional traits, each of which could characterize the figure of the "teacher leader". The four dimensions were:

- Personal relations (Statements 2 and 3)

- Pupil empowerment (Statements: 1,5 and 6)

- Personal traits (Statements: 4, 10, 12, 13, and 15)

- Functional traits (Statements: 7, 8, 9, 11 and 14).

(3) The questionnaire included a third part that required the completion of sentences with free text which would 
describe the respondents' authentic "voice". Analysis of the qualitative findings was performed by first and second cycle coding of the texts and creation of categories.

\subsubsection{The Research Method}

This was a mixed method research using quantitative and qualitative methodology based on field-grounded theory and quantitative research composed of several statistical tests.

The research paradigm argued that each student-teacher has a personal worldview of the teacher-leader. Emphasis was given to ontological research, aiming to clarify the world of defined and covert conceptualizations (images and metaphors) in the context of the concept of the teacher-leader. The quantitative part of the research employed grading agreement with statements and the qualitative part employed completion of sentences, adding an authentic personal verbal dimension to the findings.

Mixed methods methodology was chosen out of the assumption that there is a structured tension between the two types of research (qualitative and quantitative) that represents the gap between neutral grading and the expression of a personal voice. The data were gathered sequentially and after a month the online platform no longer accepted new data.

\subsection{Data Processing}

Data processing was performed with the aid of SPSS software program. At the first stage descriptive statistical indices were calculated and the reliability of the questionnaire's parts were tested. At the second stage, in order to try to answer the research questions, one-directional ANOVA tests were performed.

As noted, the research relied on mixed methods methodology including statistical data analysis for the quantitative part of the questionnaire and content analysis of the wording in the sentence completion part. In the quantitative part at the first stage, main categories were identified that emerged from the respondents' answers, and at the second stage the number of statements in each category were counted and the findings were presented in a frequencies table. At the second stage the different categories were sorted into the four main dimensions identified at the first quantitative stage. At this stage, the frequency and dominance of key words were counted (using the Atlas program).

\subsection{The Research Population}

The questionnaire was sent to all student-teachers in the teacher education college, 650 student-teachers in total. 125 chose to answer. 103 of them were female $(83.7 \%)$ and 20 were male $(16.3 \%) .57 .7 \%$ were in the regular B.Ed. program and $42.3 \%$ studied in the retraining B. Ed program. The ages of the respondents ranged between $20-59$ years $(\mathrm{M}=30.39 ; \mathrm{SD}=7.79)$.

\subsection{Findings}

The mean grade given by the respondents for the statements were calculated separately for each dimension. Table 1 presents the general means and standard deviations and also the level of reliability (tested by Cronbach's $\alpha$ ) for each of the dimensions.

Table 1. General traits, Means and standard deviations and reliability of the research dimensions $(\mathrm{N}=125)$

\begin{tabular}{llllllll}
\hline Index & No. of statements & Scale & Minimum & Maximum & Mean & SD & $\alpha$ \\
\hline Personal relations & 2 & $1-5$ & 1.00 & 5.00 & 4.75 & 0.57 & 0.883 \\
Pupil empowerment & 3 & $1-5$ & 1.00 & 5.00 & 4.50 & 0.54 & 0.684 \\
Personal traits & 5 & $1-5$ & 1.00 & 5.00 & 4.46 & 0.54 & 0.722 \\
Functional traits & 6 & $1-5$ & 1.00 & 5.00 & 4.33 & 0.60 & 0.759 \\
\hline
\end{tabular}

The mean grade given by all respondents for the Personal Relations index (4.75) was found to be the highest among all four indices. This finding includes very high grades for considerate relations and mutual trust relations that the teacher leader demonstrates towards their pupils. The second highest mean was given to Pupil Empowerment (4.50) and this was followed by the mean for Personal Traits (4.46) and the mean for Functional Traits which received the lowest grade of all four indices, but still a relatively high mean (4.33). The reliability of the indices, as measured by Cronbach's alpha $(\alpha)$ was found to be high (especially the Personal Relations index), a datum that indicates that each of the statements had strong stability and consistency. Table 2 presents the means for the respondents' answers for each statement in the questionnaire. 
Table 2. Means and standard deviations for the teacher-leader questionnaire $(\mathrm{N}=125)$

\begin{tabular}{lllll}
\hline The teacher-leader & Min. & Max. & Mean & SD \\
\hline Allows pupils to have freedom of choice and a broad range of action & 1 & 5 & 4.10 & 0.81 \\
Demonstrates consideration and respect for the pupils & 1 & 5 & 4.74 & 0.61 \\
Creates a mutual trust relationship with pupils & 1 & 5 & 4.75 & 0.61 \\
Transcends own personal interests & 1 & 5 & 4.29 & 1.03 \\
Encourages pupils to take responsibility for themselves & 1 & 5 & 4.69 & 0.64 \\
Stimulates pupils' motivation to learn & 1 & 5 & 4.72 & 0.62 \\
Able to provide a response to new problems outside their experience & 1 & 5 & 4.00 & 0.92 \\
Leading figure and oriented to the pupils & 1 & 5 & 4.73 & 0.58 \\
Unafraid of challenges & 1 & 5 & 4.27 & 0.98 \\
Charismatic & 1 & 5 & 4.46 & 0.74 \\
Functions well even in situations of pressure & 1 & 5 & 4.40 & 0.72 \\
Serves as a personal model for the pupils within the school setting & 1 & 5 & 4.73 & 0.60 \\
Is self-confident & 1 & 5 & 4.52 & 0.69 \\
Has a flexible character and can function under extreme conditions & 1 & 5 & 4.23 & 0.91 \\
Has the ability and willingness to influence others & 1 & 5 & 4.32 & 0.82 \\
\hline
\end{tabular}

The data shown in Table 2 clearly show that in the opinion of all the respondents, the teacher leader principally forms a mutual trust relationship with their pupils (4.75) and demonstrates consideration and respect towards the pupils (4.74). Moreover, it appears that according to the respondents, the "less dominant" skills of the teacher-leader are their ability to provide a response to new problems outside their experience (4.00) and the ability to allow the pupils freedom of choice and a broad space for action (4.10). Nevertheless, these attributes are also graded as high on the scale.

\subsection{Differences by Gender}

In order to examine whether there were correlations or differences between the research indices according to different demographic variables, several statistical tests were performed as follows:

\subsubsection{Differences by Gender}

In order to test whether there was a difference between the opinions of males in comparison to those of female respondents, regarding the indices for the teacher leader, $t$-tests were performed for the independent variables. Table 3 presents the means for the two groups and the results of the tests.

Table 3. Differences between males and females for the indices of the teacher-leader and results of t-tests

\begin{tabular}{|c|c|c|c|c|c|}
\hline \multirow[t]{2}{*}{ Index } & \multicolumn{2}{|c|}{ Males $(\mathrm{N}=\mathbf{2 0})$} & \multicolumn{2}{|c|}{ Females $(N=103)$} & \multirow[t]{2}{*}{$\mathbf{t}$} \\
\hline & Mean & SD & Mean & SD & \\
\hline $\mathbf{P e}$ & 4.80 & 0.50 & 4.73 & 0.59 & 0.47 \\
\hline rment & 4.42 & 0.54 & 4.52 & 0.54 & 0.81 \\
\hline Perso & 4.50 & 0.56 & 4.46 & 0.55 & 0.28 \\
\hline Functional traits & 4.30 & 0.59 & 4.34 & 0.60 & 0.29 \\
\hline
\end{tabular}

As can be seen from Table 3, no significant differences were found between the opinions of males in comparison to females for any of the four indices for the teacher leader.

\subsubsection{Differences by Years of Study}

In order to examine whether there were differences between the opinions of the respondents who were at the beginning of their academic studies (Years 1 and 2) and those who were in more advanced years of their studies (Years 3 and 4) for the indices of the teacher leader, additional t-tests were performed for the independent variables. Table 4 presents the means for these two groups and the results of the tests. 
Table 4. Differences by years of study for the indices of the teacher-leader and results of t-tests

\begin{tabular}{llllll}
\hline \multirow{2}{*}{ Index } & $\mathbf{1}^{\text {st }}$ year of studies $(\mathbf{N}=\mathbf{2 0})$ & \multicolumn{3}{c}{$\mathbf{3}^{\text {rd }}$ year of studies $(\mathbf{N}=\mathbf{4 8})$} & \multirow{2}{*}{$\mathbf{t}$} \\
\cline { 2 - 5 } & Mean & SD & Mean & SD & \\
\hline Personal relations & 4.69 & 0.65 & 4.83 & 0.42 & 1.45 \\
Pupil empowerment & 4.45 & 0.60 & 4.60 & 0.42 & 1.54 \\
Personal traits & 4.35 & 0.60 & 4.66 & 0.37 & $3.22^{* *}$ \\
Functional traits & 4.21 & 0.64 & 4.52 & 0.46 & $2.97 * *$ \\
\hline
\end{tabular}

As can be clearly seen from Table 4, respondents in Year 3 and above expressed more positive opinions with respect to the Personal Traits (4.66) of the teacher-leader, in contrast to respondents in Years 1 and 2 (4.35) in a significant manner $\mathrm{p} 0.01>\mathrm{t}(123)=3.22$ Additionally, respondents in Years 3 and above gave more positive grades for Functional Traits (4.52) of the teacher-leader p 0.01> $t(123)=2.97$ No significant differences were found for the indices: Personal Relations and Pupil Empowerment.

\subsubsection{Differences by Academic Stream}

In order to examine whether there were differences between the opinions of the respondents who were studying in the regular teacher-education stream and those who were studying in the retraining stream for the indices of the teacher-leader, additional $t$-tests were performed for the independent variables. Table 5 presents the means for these two groups and the results of the tests.

Table 5. Differences by academic stream for the indices of the teacher-leader and results of t-tests

\begin{tabular}{llllll}
\hline \multirow{2}{*}{ Index } & \multicolumn{3}{l}{ Regular stream $(\mathbf{N}=\mathbf{7 1})$} & \multicolumn{3}{l}{ Retraining stream $(\mathbf{N}=52)$} & \\
\cline { 2 - 5 } & Mean & SD & Mean & SD & t \\
\hline Personal relations & 4.81 & 0.43 & 4.65 & 0.72 & 1.38 \\
Pupil empowerment & 4.59 & 0.43 & 4.39 & 0.65 & $2.06^{*}$ \\
Personal traits & 4.55 & 0.47 & 4.34 & 0.62 & $2.11^{*}$ \\
Functional traits & 4.42 & 0.52 & 4.21 & 0.67 & 1.97 \\
\hline
\end{tabular}

$*-\mathrm{p}<0.05$

The data in Table 5 indicates that the respondents in the regular stream expressed more positive opinions regarding Pupil Empowerment by the teacher leader (4.59), in comparison with respondents in the retraining stream (4.39) and in a significant manner p 0.05 $>\mathrm{t}(121)=2.06$. Additionally, respondents in the regular stream gave more positive grades for the Personal Relations of the teacher-leader (4.55) in comparison with respondents in the retraining stream (4.34) and in a significant manner p.0.05 $>\mathrm{t}(123)=2.11$. No significant differences were found for the indices: Personal Traits and Functional Traits.

\subsubsection{Correlation with Age}

In order to examine whether there were correlations between the research indices and the respondents' ages, Pearson correlations were calculated. Table 6 shows the correlations that were found.

Table 6. Pearson correlations examining the correlations between the different research indices and respondents' ages

\begin{tabular}{|c|c|}
\hline Index & Correlation with Respondents' Age \\
\hline Personal relations & $-0.208^{*}$ \\
\hline Pupil empowerment & -0.155 \\
\hline Personal traits & -0.175 \\
\hline Functional traits & -0.164 \\
\hline
\end{tabular}

$*-\mathrm{p}<0.05$

A significant negative correlation at a low strength was found between the respondents' opinions concerning the Personal Relations of the teacher leader and the respondents' ages $\mathrm{r}=-\mathrm{p} \mathbf{0 . 0 1}>0.208$, such that insofar as the respondent is older than their grades for Personal Relations of the teacher-leader will be more negative. The other correlations between the respondents' age and their opinions concerning the teacher-leader's attributes were also found to be negative but not significantly so. All the indices that were tested were given very high grades. 
The index Personal Relations received the highest grades. The perception of the teacher leader that emerges from this analysis has very high quality traits, while the teacher-leader that creates Personal Relations with their students receives the strongest support.

\subsubsection{Analysis of the Qualitative Findings}

The second part of the questionnaire consisted of sentences that the respondents were asked to complete. The sentences were:

1. Leadership is ...

2. A good teacher is one who ...

3. I would like to be a teacher, that ...

4. My purpose as a teacher is ...

The responses of the respondents underwent content analysis in line with the research approach that combines formal statistics with qualitative data analysis (Bauer \& Gaskel, 2011). The content analysis process necessitated the construction of a system of categories created through a search for outstanding components, in line with theory and the studied material (Sabar Ben-Yehoshua, 1990). The purpose of this technique is to deduce conclusions from the written text in the context of and to supplement the quantitative findings that were described above. The statements were read several times, marked and coded. At the first stage the student-teachers' completions of four sentences were analyzed. Some of them included irrelevant or general statements, one-word answers in contrast to longer answers. The responses were encoded in categories for the later presentation of the findings, in line with the four main content categories determined in the closed-ended questionnaire: (1) Personal Relations, (2) Student Empowerment (3) Personal Traits and (4) Functional Traits. At the second stage content analysis was conducted on relevant responses to the sentence completion. It should be noted that some of the answers included compositions that combined several themes. The analysis of these verbal findings appears in Table 7.

Table 7. Verbal responses to the open-ended questions (no. of respondents in each category)

\begin{tabular}{lllll}
\hline Category & Leadership is ... & A good teacher is ... & $\begin{array}{l}\text { I would like to } \\
\text { be a teacher who .... }\end{array}$ & $\begin{array}{l}\text { My educational goal } \\
\text { as a teacher is... }\end{array}$ \\
\hline Personal relations & $\mathbf{3}$ & $\mathbf{2}$ & $\mathbf{1 0}$ & $\mathbf{3}$ \\
Pupil empowerment & 9 & 16 & 9 & 32 \\
Personal traits & 32 & 34 & 22 & 2 \\
Functional traits & $\mathbf{1 6}$ & $\mathbf{7}$ & $\mathbf{6}$ & $\mathbf{2 2}$ \\
\hline
\end{tabular}

The total number of appearances of the different statements was calculated and the results are presented in Figure 1 below.

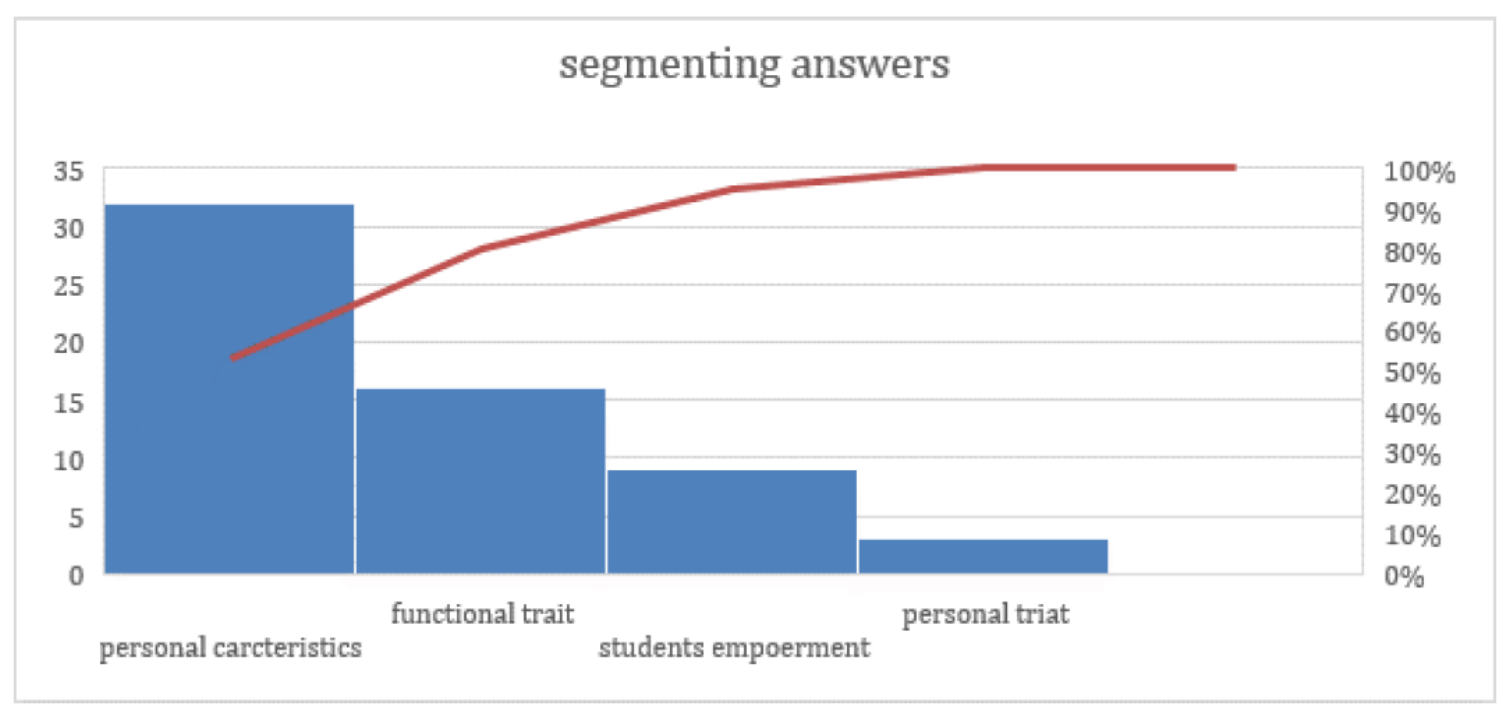

Figure 1. Appearance of the dimensions in the content analysis

Calculation of all the answers indicates that most students gave a very central place, with a significant gap from 
other traits for Personality Traits (90 phrases) as a characteristic of the leadership role. This qualitative finding differed from the quantitative findings (where the highest rank was given to Personal Relations).

\subsection{Metaphorical Thinking in Relation to the Concept of "Teacher-leader": Key Findings}

Analysis of the phrases that expressed metaphorical thinking concerning the concept of "teacher leader" identified several categories as displayed in Table 8.

Table 8. Category and commentary analysis

\begin{tabular}{|c|c|c|}
\hline Category & Example citations & Interpretation \\
\hline Abstract pictures & $\begin{array}{l}\text { "The ability to draw a future picture" } \\
\text { "To leave their mark on the child that will } \\
\text { accompany them along their path" } \\
\text { "Like a swelling and sweeping sea" } \\
\text { Leading }\end{array}$ & $\begin{array}{l}\text { Many uses of text that represents } \\
\text { the teacher's active activity and } \\
\text { their impact on the student, } \\
\text { especially student empowerment. } \\
\text { This is mainly indicative of a } \\
\text { moral worldview of the teaching } \\
\text { profession perceived as } \\
\text { educational leadership. } \\
\text { A broader, descriptive and } \\
\text { creative worldview. }\end{array}$ \\
\hline $\begin{array}{l}\text { Professional } \\
\text { leadership }\end{array}$ & $\begin{array}{l}\text { Leadership of famous people - noting names, } \\
\text { for example: Ben Gurion, especially statesmen }\end{array}$ & $\begin{array}{l}\text { Use of simile comparing the } \\
\text { teacher-leader to well-known }\end{array}$ \\
\hline $\begin{array}{l}\text { Famous leaders in } \\
\text { culture, the army or } \\
\text { religion or leadership } \\
\text { professions }\end{array}$ & $\begin{array}{l}\text { Religious/Spiritual Leaders - Moses and the } \\
\text { goat, the Dalei Lama } \\
\text { Leadership professions - The Pied Piper of } \\
\text { Hamlin, a captain, orchestra conductor, a driver } \\
\text { leading his car along the correct path according } \\
\text { to traffic regulations, leader of a musical group. }\end{array}$ & $\begin{array}{l}\text { consensual leading figures } \\
\text { OR } \\
\text { Professionals whose role involves } \\
\text { leading and direction. } \\
\text { Representing a more conservative } \\
\text { worldview rooted in existing } \\
\text { inspiring models }\end{array}$ \\
\hline $\begin{array}{l}\text { Functional } \\
\text { simplification } \\
\text { Use of objects and } \\
\text { elements in order to } \\
\text { represent direction or } \\
\text { leaders }\end{array}$ & $\begin{array}{l}\text { Spearhead, Lighthouse, Driving wheel, Pillar of } \\
\text { defense. }\end{array}$ & $\begin{array}{l}\text { Objects that have symbolic } \\
\text { meaning for teaching a path, } \\
\text { direction, leadership } \\
\text { A simple and concise image. }\end{array}$ \\
\hline
\end{tabular}

The content analysis presented in Table 8 presents three main categories that are characterized by: 1 . using an explicit richly worded verbal image in an attempt to provide a broad definition of educational leadership. 2 . Metaphors dealing with well-known figures of leaders or types characterized by the ability to lead.

It was also found that the word "leader" with all its derivatives and biases appeared as very dominant (40 mentions) in a variety of contexts of educational practice. Here are some examples: "Leading the pupils to a good path and achievement", "Leading the class to the best possible achievement and most importantly making the little ones the best people possible". "The ability to drive and lead change, something that every teacher needs to develop. Leading pupils to positive change while staying true to myself... authentic without masks", "not only the ability to lead the child to realize his or her maximum potential, but also to lead their colleagues and staffs to formulate educational ideas and to change and improve the educational climate, to allow better and deeper education for the new generation". "Educational leadership, in my opinion, is to lead, educate, contribute, inspire and curiosity and interest in everything."

These findings are in line with descriptive research approaches concerning the term "leader" as described by Vygotsky (2004): "The teacher leader leads the learning processes." Or as described by Darling -Hammond (2005) who compared the teacher to the "conductor of the orchestra organizing learning". Another category is characterized by the use of inanimate objects as symbols, comparing the leader to an object whose role is to show the way, a leader, leading and directing others.

But content analysis and categorization are not enough. The method used here seeks to discover the student-teachers' general perceptions concerning the concept of "teacher leader" and therefore, it touches on a "superficial" (ground level) layer and does not delve deeply into the complex interpretations and strata found in 
each and every metaphor category. A follow-up investigation is needed to examine the meanings of each metaphor separately and each set of metaphor categories. This can reveal something not only about the respondents' perceptions, but also their worldviews of leadership. For example, can the metaphor indicate personal constraints inhibitions, cultural perceptions, situational propositions and solutions, personal elements? Can it also indicate something about the nature of the relationship between the leader and the leaders, in the presently discussed case of the teacher and their pupils? Such an examination could be significant and very valuable.

As illustrated in Table 8, each category of metaphors can be assigned a different interpretation indicating the respondent's unique viewpoints, personal traits, worldview, and values or, alternatively, a narrow worldview described in a word or two, in a representative object or figure for imitation. This kind of analysis opens the door to a preliminary and more general observation of the leader's image from the perspective of the respondents, the future teachers. It is important to emphasize that this interpretation must be treated with caution, because often the use of metaphor is associative, spontaneous and without any deep awareness by the respondent. However, this tool is important and thickens and enables expanded understanding of various issues beyond dry numbers and data.

\section{Discussion}

The purpose of the research was to investigate perceptions of the teacher-leader described by student-teachers training to be teachers and educators in various professional roles.

1. How do the student-teachers define the main traits that compose the figure of the "teacher leader"?

In response to this question it was found that the teacher leader was seen especially as creating mutual trust with the pupils (4.75), demonstrating consideration and respect towards the pupils (4.74). The traits of the teacher leader that received "less dominance" were the ability to provide a response to new problems outside their previous experience (4.00) and the ability to give pupils free choice and a broad space for action (4.10). However, these traits also received high grades.

2. How do they see the desirable figure of the "teacher leader"? What are the most dominant leadership/meaningful traits of this figure?

In response to this question the respondents' portrayed an image whose most dominant characteristic was Personal Relations. This index received the highest grade (4.69), followed by Pupil Empowerment (4.45), Personal Traits (4.35) and Functional Traits (4.21). These findings are supported by the theoretical approach of Oplatka (2015), who argued that "orientation to people includes leadership behavior that creates a sense of camaraderie, trust, warmth, interest and respect in the relationship between the leader and their subordinates, task-oriented behavior but innovative. It includes leadership behavior that creates defined types of work organization, communication channels and work methods". He also notes that "leader-subordinates relations relates to the quality of relations between the leader and their group, in general this is the extent of security, trust and respect that the leader provides for their subordinates, and they for him. The assumption is that respect and admiration for the leader reinforce their influence and power in the group" (Oplatka, 2015).

3. Which metaphors do the student-teachers use to reflectively define the figure of the "teacher-leader"? This third question aimed to examine the way in which the student-teachers reflectively perceived themselves as teacher leaders through qualitative content analysis and analysis of the metaphors dispersed through the respondents' different completion of sentences. This analysis provided a deepening dimension to the quantitative-numerical data: findings that emerged from the quantitative part, where all the categories received very high grades, characterizing an idealistic observation that sees the image of the teacher leader as the desired ideal. As appears from all the answers it seems that the student-teachers tend to glorify the concept of the "teacher leader" looking up towards this image as if it were exalted.

The qualitative part of the research permitted free, authentic, personal and subjective expression by the respondents. It can be assumed that this free independent and associative expression in a reflective and open theoretical manner, reflected the respondents' perceptions concerning the concept of "teacher leader". Here it is possible to see a more descriptive, metaphorical and practical expression that may explain the gaps in grades given to the different content categories, whereby each respondent tries to "drown" their own vision of the teacher leader.

In general. the student-teachers' viewpoints as they emerged from all the findings, can be seen as being in line with the theoretical approach described in the model that sets standards for the teacher leader's image: the Standard Teacher Leader Model (Teacher Leadership Exploratory Consortium 2011). This model is based on the 
extent of the teacher leader's influence on teaching and learning practices, leading to pupil empowerment, expressed in the improvement of the pupil's academic achievements. Similar traits can also be identified in the approach of Cohen (2011) who indicates that the image of the teacher leader should be seen as a model for imitation, a charismatic person, with knowledge and vision. He is therefore characterized by: charisma, personal relations, presenting intellectual challenges and a vision to the pupils, in the form of the setting of concrete goals beyond the pupil's personal goal. In other words, the teacher leader uses their abilities, and attributes to establish a system that empowers and challenges the pupils.

To summarize: the image of the teacher leader as outlined by the student-teachers was characterized as moving along two main axes, the ideal and sublime in contrast to what is desirable and appropriate. The general and theoretical as opposed to the personal and individual revealed in the student's "self" as a future teacher.

\section{Conclusions}

1. The student-teachers' viewpoints concerning the image of the teacher leader ranged along several axes, and painted an exalted image graded as very high on all the studied indices. In the quantitative analysis it was seen that the highest grades were given to Personal Relations.

2. In the qualitative analysis of the worded responses, that included the completion of sentences from a more personal viewpoint that uses the language of "the self ", it was possible to see that the category of Personal Traits was awarded the highest grades.

3. It can be deduced that the image of the "teacher leader" is seen as an exalted high-quality image with a characteristic of giving. However, when the students apply this concept to themselves, reflectively as in "I the teacher leader" then it can be seen that a transformation occurs in their consideration referring more to reasonable personal and more human traits, closer to reality than the exalted image.

4. It is possible that the gap between the quantitative and qualitative finding can be understood by the gap between subjectivity and objectivity, between the exalted-theoretical image and the personal and more human image. It should be noted that both of these measures: The Personal Traits and Personal Relations were very significant.

5. Analysis of the different findings indicates that insofar as the respondent was older, then their view concerning the teacher leader's Personal Relations would be more negative. This finding indicates the diminution of the idealistic perception as the respondent becomes older and more experienced in educational work. It may be possible to identify an erosive process here, whereby the gap in findings is fed by the gap between the ideal and the reality, the theory in the protected hothouse of training in contrast to the "shock of the live classroom". Follow-up research is needed to test this thesis.

6. All the studied indices were awarded very high grades. The index Personal Relations was given outstandingly highest grades. These findings yield an image of the teacher leader with very high-quality traits, and above all the image of a teacher leader who gives his pupils personal consideration.

7. As noted, the different (quantitative and qualitative) findings describe leadership skills required by the teacher leader to fulfil their role. These findings exemplify the student-teachers' viewpoints, through their analogical thinking that projects from one area to another.

8. Analysis of all the findings indicates that there is a structured tension that represents the gap between what is desirable and what exists in reality, between the sublime theoretical ideal, and the complex and complicated reality. Thus, teacher training processes and especially their practicum in the education field and student-teachers' exposure to a broad range of human and not just theoretical models all play a central role in the reduction of this gap and the shaping of a more realistic understanding of the concept "teacher leader".

9. Deep follow-up research is needed to investigate and interpret all the metaphor categories.

\section{Recommendations}

1. To teach and instruct student-teachers in teacher training programs concerning what is expected from them as significant leadership figures in education.

2. To develop learning communities to support student-teachers and guide them to perform initiatives and acquire skills needed for educational leadership.

3. Professional learning and development for those who are suitable to lead and act as educational leaders.

4. To encourage the use of data-based evaluation processes.

5. To encourage development processes at an individual level, and improvement of interpersonal communication. 
6. To encourage the student-teachers' involvement during the training process in the community, with pupils' families to develop and empower the dimension of interpersonal relations, social awareness, and various collaborations outside the school classroom.

7. To create an appropriate profile for the concept of the "teacher leader" in terms of the ideal and desirable image to which the student-teachers should aspire and to guide them to those standards.

The Study's Limitations

1. The research was conducted in a population studying in a single education and teaching college. The population is characterized by belonging to the northern geographic region of the State of Israel.

2. The research data were collected with the use of a questionnaire which asked respondents to define the image of the teacher leader according to four categories and in open-ended questions. Research that uses many questions or an open-ended questionnaire relating to a broader variety of different areas might have produced other results.

3. Data-collection was conducted online and anonymously, perhaps a face-to-face interview would have produced different results or would have thickened the data that were produced.

\section{References}

Adams, D., Raman, K. G., \& Mohd, Z. Z. (2017). Educational leadership for the 21st Century. International Online Journal of Educational Leadership, 1(1), 1-4. https://doi.org/10.22452/iojel.vol1no1.1

Agosto, V., \& Roland, E. (2018). Intersectionality and educational leadership: A Critical Review. Review of Research in Education, 42(1), 255-285 https://doi.org/10.3102/0091732X18762433

Apelwig, N., \& Shalev-Wigisar, I. (2010). The role of the teacher at the beginning of the $21^{\text {st }}$ century. Jerusalem: Van Leer Institute.

Brown, J. (1993). Leadership for school improvement. Emergency Librarian, 20(3), 8-20.

Cohen, A. (2011). The viewpoints of teachers: On teachers' development and leadership of principals intended to improve teaching. Israel: Avney Rasha Knowledge Center.

Darling-Hammond, L., \& Bransford, J. (Eds.) (2005). The design of teacher education programs: Preparing Teachers for a Changing World. CA: Jossey Bass.

Darom, D. (2003). A climate of growth. Bnei Brak: Sifriat Hapoalim, and Kibbutz Artzi-Hashomer Hatzair.

Eyal, L. (2014). A practical model for the shaping of the professional identity of an educator as a leader leading change. The Mofe't Institute Journal, 53, 45-50.

Harpaz, I. (2009). Hey, We're really not in the right direction!, Hed Hinuch, 4, 82-87.

Harrison, C., \& Killion, J. (2007). Ten roles for teacher leaders. Educational Leadership, 65(1), 74-77

Humphreys, E. (2010). Distributed leadership and its impact on teaching and learning. Unpublished dissertation, NIU Maynooth University, Ireland.

Levi, A. (2008). Management and leadership of change and innovation. Israel: Rimonim Publishers.

Lakoff, G., \& Johnson, M. (1980). Metaphors we live by. University of Chicago Press.

Mayer-Schoenberger, V., \& Oberlechner, T. (2002). Through their own words: Towards a new understanding of leadership through metaphors. KSG Working Papers Series RWP02-043. http://dx.doi.org/10.2139/ssrn.357542

Nissim, Y., \& Simon, E. (2019). The teacher-leader's image: Between personal characteristics and strategies empowering learners. Journal of Education and Learning, 8(3). https://doi.org/10.5539/jel.v8n3p136

Noonan, S., \& Fish, T. (2004). Metaphors of leadership. Paper presented at the annual meeting of the National Council of Professors of Educational Administration, Branson, Missouri, August.

Oplatka, I. (2015). Basics of educational management: Leadership and management in an educational organization. Israel: Pardess Publications Ltd.

Paras, M., Cohen, T., Dashevsky, A., Fruchter, A. Z., Havi, A., Perl, B., \& Aliyan, S. (2005). Teacher training in Israel - Who is the good teacher. Albustan, 4, 19-36.

Perry, A. I. (2006). The position of leadership in the students' perception of the good teacher. Retrieved from http://www.hebpsy.net/articles.asp?id=940 
Raichal, N., \& Arnon, S. (2005). Three portraits of teachers mirrored by the student-teacher - the ideal teacher, the teacher educator and the student's self-image as a teacher, Daim, 40, 23-58.

Singh, K. (2010). Metaphor as a tool in educational leadership classrooms. Management in Education, 24(3), 127-131. https://doi.org/10.1177/0892020608090411

Schneider, A., \& Yitzhak-Mossongen, A. (2010). Emotional-intellectual orientation and insight in human relations, a substantive layer in the perception of school administration. Kfar Saba: Beit Berl Academic College, The Unit for Research and Evaluation.

Shatz-Oppenheimer, O. (2006). The teacher's roles in a heterogeneous classroom according to Karl Frankenstein's educational approach. Mifgash, 24, 120-107

Teacher Leadership Exploratory Consortium (2011). Teacher Leader Model Standard. Retrieved from https://www.ets.org/s/education_topics/teaching_quality/pdf/teacher_leader_model_standards.pdf

Yukl, G. (2010). Leadership in organizations. 7th ed. Upper Saddle River, N.J.: Pearson.

Vygotsky, L. S. (2004). Imagination and creativity in childhood. Journal of Russian and East European Psychology, 42(1), 7-97. https://doi.org/10.1080/10610405.2004.11059210

\section{Copyrights}

Copyright for this article is retained by the author(s), with first publication rights granted to the journal.

This is an open-access article distributed under the terms and conditions of the Creative Commons Attribution license (http://creativecommons.org/licenses/by/4.0/). 